\title{
Tumor resistance to vascular disrupting agents: mechanisms, imaging, and solutions
}

\author{
Wenjie Liang ${ }^{1}$, Yicheng $\mathrm{Ni}^{2}$ and Feng Chen ${ }^{1}$ \\ ${ }^{1}$ Department of Radiology, The First Affiliated Hospital, School of Medicine, Zhejiang University, Hangzhou, Zhejiang, China \\ 2 Radiology Section, University Hospitals, University of Leuven, Leuven, Belgium \\ Correspondence to: Feng Chen, email: chenfenghz@zju.edu.cn
}

Keywords: vascular disrupting agents, resistance, imaging, solutions

Received: September 27, $2015 \quad$ Accepted: January 14, $2016 \quad$ Published: January 22, 2016

\section{ABSTRACT}

The emergence of vascular disrupting agents (VDAs) is a significant advance in the treatment of solid tumors. VDAs induce rapid and selective shutdown of tumor blood flow resulting in massive necrosis. However, a viable marginal tumor rim always remains after VDA treatment and is a major cause of recurrence. In this review, we discuss the mechanisms involved in the resistance of solid tumors to VDAs. Hypoxia, tumor-associated macrophages, and bone marrow-derived circulating endothelial progenitor cells all may contribute to resistance. Resistance can be monitored using magnetic resonance imaging markers. The various solutions proposed to manage tumor resistance to VDAs emphasize combining these agents with other approaches including antiangiogenic agents, chemotherapy, radiotherapy, radioimmunotherapy, and sequential dual-targeting internal radiotherapy.

\section{INTRODUCTION}

The emergence of small molecule agents that target the tumor vasculature is an advance in the treatment of malignant solid tumors [1-3]. Antivascular drugs can be divided into two types according to the molecular target strategy: antiangiogenic agents and vascular disrupting agents (VDAs). Antiangiogenic agents act on the signaling pathways between tumor cells, endothelial cells (ECs), and stromal cells to inhibit the formation of new blood vessels $[4,5]$. The United States Food and Drug Administration (FDA) has approved several antiangiogenic agents such as bevacizumab, sunitinib, and sorafenib. However, they are not the focus of this review. Small molecule VDAs kill tumor cells by inducing rapid and selective shutdown of tumor blood flow. Although VDAs have not been approved by the FDA, they have shown significant therapeutic potential and are a focus of current research [6]. VDAs mainly include tubulin-binding agents such as combretastatins and drugs related to 5, 6-dimethylxanthenone-4-acetic acid (DMXAA). Combretastatin A-4 3-O-phosphate (CA4P; the lead combretastatin) and its derivatives such as the more effective CA1P (Oxi4503) and synthetic analogue AVE8062 are currently in preclinical and clinical development [6]. Despite the encouraging therapeutic effects of VDAs, clinical trials have shown that residual marginal tumor cells are less sensitive to CA4P [7] and can survive nutrient-deficient conditions. Moreover, the viable marginal tumor cells are a major cause of recurrence and metastasis $[6,7]$ and are indicative of resistance to VDAs $[8,9]$.

In this review, we summarize the mechanisms involved in the resistance of solid tumors to VDAs, the role of imaging markers in visualizing and understanding resistance, and the various solutions proposed to overcome tumor resistance to VDAs.

\section{MECHANISMS OF SOLID TUMOR RESISTANCE TO VASCULAR DISRUPTING AGENTS}

Residual viable tumor rim and hypoxia

The VDA-induced rapid shutdown of the tumor vasculature leads to massive central tumor necrosis. The entire tumor, including the necrotic portion and residual viable rim, become hypoxic due to the reduced blood supply $[10,11]$. Thus, hypoxia may be one of the key factors that contribute to VDA resistance. Since the residual viable tumor cells may obtain oxygen and nutrients from nearby blood vessels in the normal tissue, 
they can metabolically adapt to hypoxic conditions and become hypoxia-tolerant. According to El-Emir et al. [11], hypoxia reaches a maximum at both the central and peripheral portions of a tumor 1 hour after CA-4P administration. It is then alleviated after 24 hours and is restricted to regions adjacent to the central necrotic area. Hypoxia results in upregulation of the expression of hypoxia inducible factor $1 \alpha$ (HIF- $\alpha)$, which activates transcription of a large panel of genes involved in angiogenesis and increases the levels of circulating proangiogenic cytokines including vascular endothelial growth factor (VEGF) and stromal derived factor $1 \alpha$ $(\mathrm{SDF}-1 \alpha)$ [12]. Experiments with tumor-bearing animals have confirmed that after VDA treatment, the levels of VEGF and basic fibroblast growth factor increased significantly [13-15]. Newly formed tumor vessels provide nutrients for residual peripheral tumor cells and promote growth and proliferation. Under hypoxic conditions, HIF$1 \alpha$ is also involved in glycolysis and the microenvironment acidification of tumors, which influence both cell survival and cell death. Thus, HIF-1 $\alpha$ drives tumorigenesis and metastasis $[16,17]$.

Long-term follow-up of clear-cell carcinoma patients who underwent radical nephrectomy showed that VEGF and HIF-1 $\alpha$ were closely related to prognosis, and that VEGF was an independent predictor of prognosis [18]. The enhanced invasiveness of HIF-1 $\alpha$-induced tumor cells has been demonstrated in vitro [19]. Another study confirmed that HIF-1 $\alpha$ could independently increase the malignant potential of a hypoxia-tolerant tumor cell line [20]. Under anoxic conditions, tumor cells have been shown to express C-X-C chemokine receptor type 4, which may also enhance the malignant potential of tumor cells via the relevant signaling pathways [21-23].

\section{Tumor-associated macrophages}

Tumor-associated macrophages (TAMs) are circulating monocyte- or resident tissue macrophagederived cells. Although TAMs are thought to promote angiogenesis, they may function antagonistically (i.e., exert either pro- or antitumor effects). For instance, Welford et al. [24] showed that there was an increase in SDF-1- and TIE2-expressing macrophages (TEMs), a proangiogenic subset of TAMs, with CA4P treatment, suggesting that TEMs could limit the therapeutic efficacy of CA4P in tumor-bearing mice. Other studies have demonstrated similar results $[25,26]$. However, Jassar et al. [27] showed that DMXAA directly activates TAMs and induces an effective antitumor response in murine models of lung cancer and mesothelioma. Wallace et al. [28] confirmed the finding that DMXAA activates dendritic cells and induces cytotoxic antitumor effects. Therefore, TAMs may have different roles with respect to the therapeutic effects of VDAs.

\section{Bone marrow-derived circulating endothelial progenitor cells}

Circulating endothelial progenitor cells (CEPs) are bone marrow (BM)-derived immature endothelial cells in the peripheral blood and account for a small proportion of circulating endothelial cells (CECs). CEPs are defined by cell surface expression of vascular endothelial cadherin, dim CD31 and CD45, CD34, CD133, and vascular endothelial growth factor receptor-2 (VEGFR-2 or KDR in humans; flk-1 in mice) [29-31]. The VDA-induced mobilization of BM-derived CEPs was first reported in an animal study [32]. After tumor-bearing mice were treated with the VDA derivative OXi-4503, the CEP count increased significantly and reached a peak 4 hours after treatment. The CEPs appeared to home to sites of viable tumor cells where they incorporated into the endothelial cells of tumor vessels and promoted tumor vasculogenesis [32]. Thus, tumors may become resistant to VDAs through a CEP-related mechanism.

The phenomenon of VDA-induced CEP mobilization has also been reported in humans. For example, Farace et al. [33] determined that CEP levels increased to various extents 3 to 7 days after treatment with AVE8062 in patients with solid tumors. In contrast to the findings of Shaked et al. [29] and Farace et al. [32, 33], Taylor et al. [8] observed two spikes in CEP levels in different tumor-bearing animal models in which the animals were treated with VDAs. An early increase in CEP levels was observed 2 to 4 hours after CA4P treatment, and a rapid and significant rise in CEP levels occurred 72 or 96 hours after CA4P treatment compared to the levels after 4 hours. The early CEP peak suggested a general host response to CA4P because it was detected in both tumor- and non-tumor-bearing animals. However, the late increase in CEPs reflected the specific VDA-induced tumor responses of vascular repair and regrowth because the delayed increase in CEP levels was exclusively observed in tumor-bearing animals, and was verified in different animal species and tumor models [8]. The second spike in CEPs reportedly parallels elevated levels of serum granulocyte colony-stimulating factor (G-CSF), matrix metallopeptidase-9 (MMP-9), and bone marrow stromalderived factor-1 (SDF-1) [34-37], suggesting that these three proteins could promote the delayed mobilization of CEPs to the peripheral circulation after VDA treatment.

The theory of VDA-induced CEP mobilization has been challenged by the conflicting results of other studies [8, 38, 39]. Ziegelhoeffer et al. [40] investigated the relationship between BM-derived cells expressing enhanced green fluorescent protein (GFP) and new vessels in murine hind limb ischemia and tumor models, and failed to find any endothelial or smooth muscle cells displaying GFP signals. Although some GFP-positive cells were observed in the local ischemic area, they were identified as fibroblasts, pericytes, or leukocytes rather 
than endothelial cells. They concluded that BM-derived cells do not incorporate into the adult growing vasculature, but may function as supporting cells. Göthert et al. [41] traced the origin of the tumor endothelium in a transgenic murine model and determined that no BM-derived cells contributed to the tumor endothelium.

Purhonen et al. [39] induced angiogenesis in four different genetically tagged mouse models and studied the mobilization of BM-derived cells to the endothelium activated by VEGF and tumors. Interestingly, they observed many BM-derived cells surrounding endothelial cells in blood vessel walls, but did not observe incorporation of these cells into the endothelium. They also did not observe mobilization of BM-derived VEGFR-2 ${ }^{+}$cells into the circulation and concluded that tumor growth does not require BM-derived CEPs. Many of these studies challenged the theory that CEPs are involved in tumor vasculogenesis, although VDAs were not used to induce BM-derived CEP mobilization in these studies. However, in a rat liver xenograft tumor model treated with ZD6126, Chen et al. [12] found that VDA treatment did not induce a significant increase in CEPs or

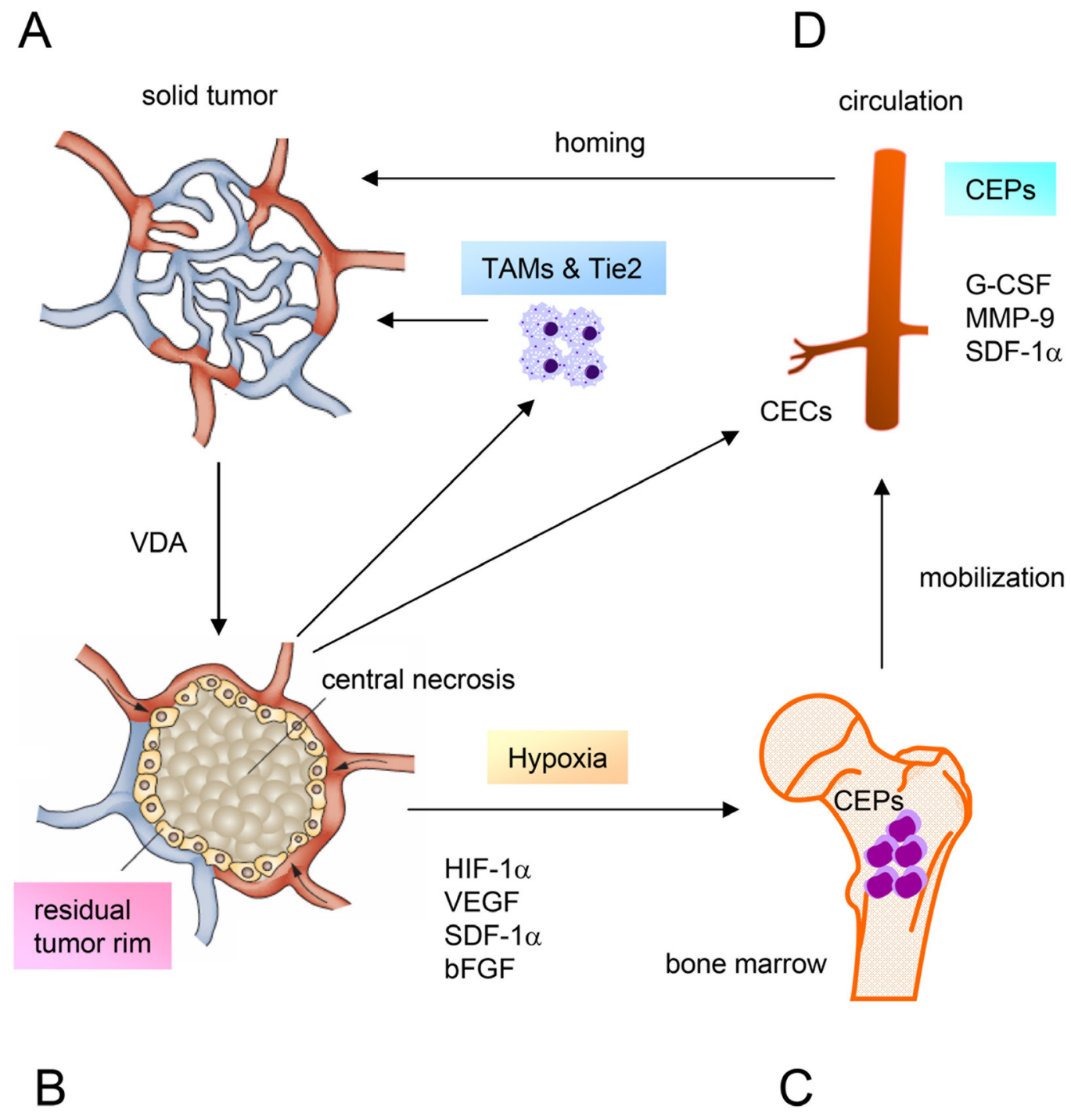

Figure 1: Diagram illustrating the mechanisms of tumor resistance to vascular disrupting agents. A. Solid tumor treated with a VDA. B. VDA-induced central necrosis and a residual viable tumor rim. Hypoxia upregulates the expression of HIF-1 $\alpha$, which increases the levels of a number of circulating proangiogenic cytokines and chemokines. C. Activation of proangiogenic pathways mobilizes BM-derived CEPs into the circulation, and is accompanied by increases in serum G-CSF, MMP-9, and SDF-1 $\alpha$. CEC levels increase due to irreversible injury of the tumor vasculature caused by VDA treatment. D. CEPs are attracted to the tumor where they incorporate into the endothelial cells of tumor vessels and promote vasculogenesis. The increased levels of TAMs and TEMs induced by VDAs limit the therapeutic efficacy. Thus, all of these factors contribute to the resistance of tumors to VDAs. Adapted from Health VL, Bicknell, R. Anticancer strategies involving the vasculature. Nature Reviews Clinical Oncology. 2009; 6: 395-404 (Figure 1) and Schmid MC, Varner JA. Myeloid cells in the tumor microenvironment: modulation of tumor angiogenesis and tumor inflammation. Journal of Oncology. 2010; 201026: 1-10 (Figure 2). 
plasma SDF-1 $\alpha 4$ hours or 2 days following therapy.

There are a number of possible explanations for the above-mentioned conflicting results. First, there may have been some false-positives regarding the identification of CEPs in earlier studies due to the signal superimposition of vessel wall CEPs and adjacent hematopoietic cells [40]. Second, as reported in some studies [39, 40], BM-derived cells were recruited only as perivascular supporting cells or pericytes. They occasionally expressed CEP markers, but did not form part of the endothelium during angiogenesis. Therefore, pericytes that originated from hematopoietic cells may have been misidentified as BM-derived CEPs. Third, several reports have indicated that mobilization of BM-derived CEPs only occurs in certain tumors [34], and little is known about which types of tumors are mainly reliant on CEPs for growth [31]. In addition, the VDA-induced mobilization of CEPs has been observed in murine models and human studies $[32,33]$, but not in rat studies [12]. Therefore, it is still unclear whether the response of CEPs to VDA treatment

\section{pre}
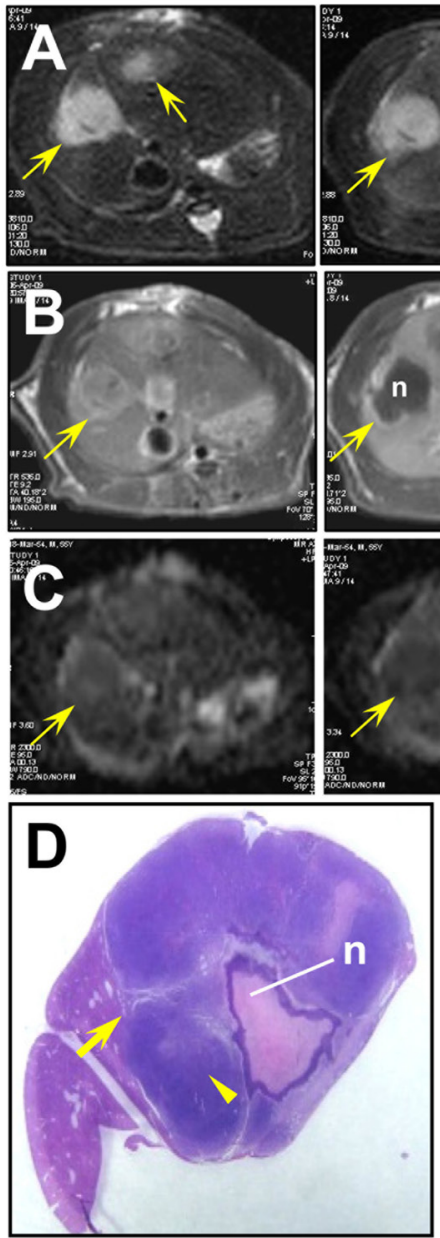

$4 \mathrm{~h}$
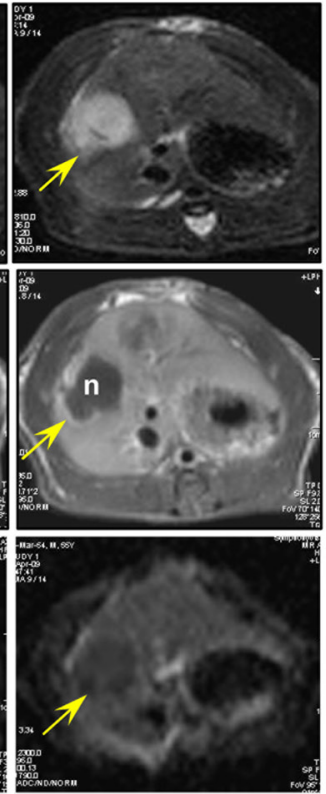

2d
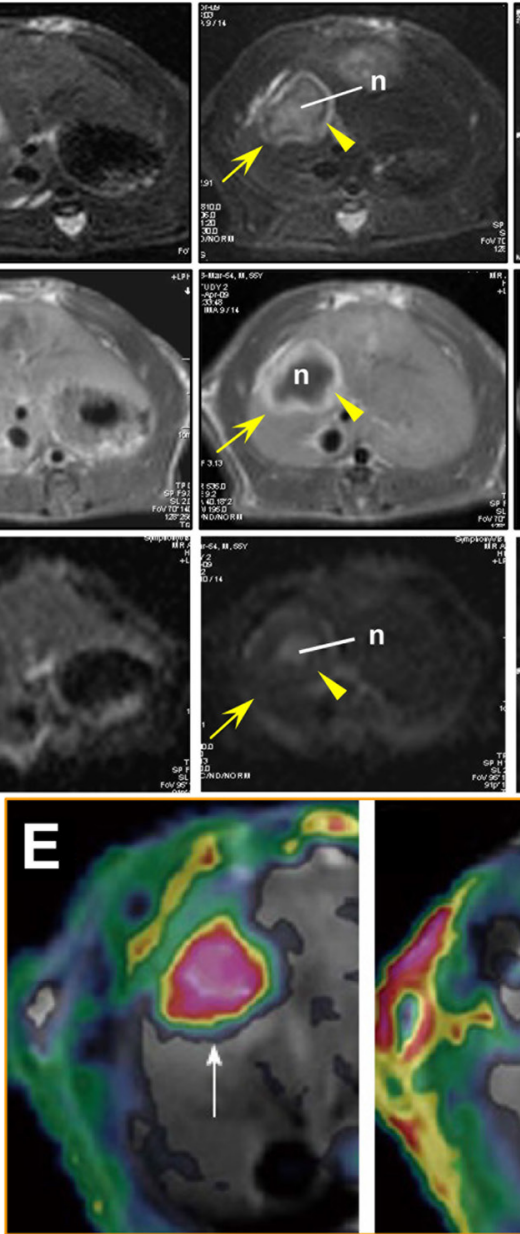

pre

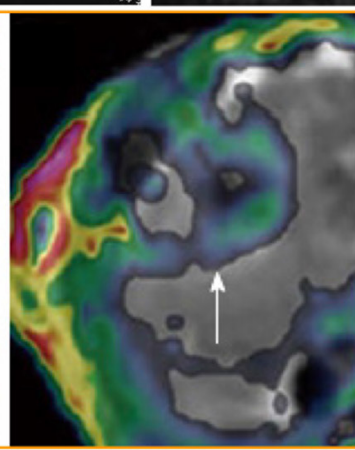

$6 h$
$6 d$
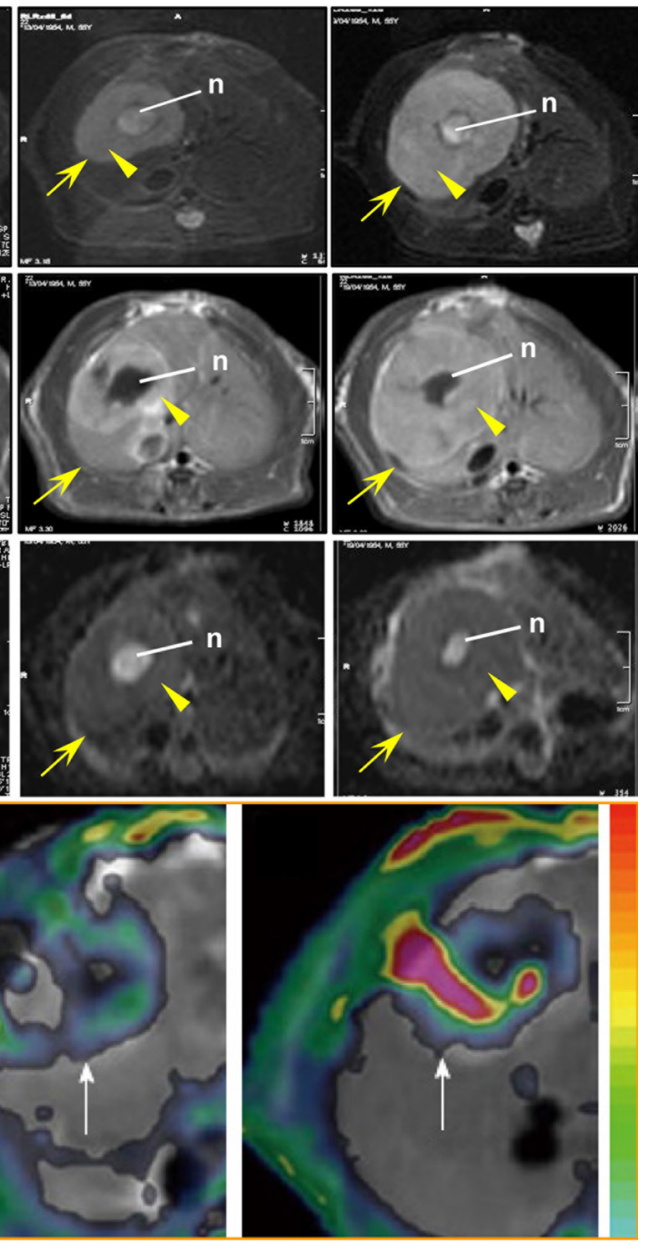

2d

Figure 2: Imaging of tumor resistance to vascular disrupting agents in a rat liver tumor model. A. MRI T2WIs show the tumor (arrow), central necrosis (n), and the viable rim (arrowhead) 2 days after ZD6126 treatment. Note the rapid regrowth of the tumor rim from 4 hours (h) to 12 days (d). B. On CE-T1WIs, the tumor rim (arrowhead) exhibits hyperintense enhancement after injection of a contrast agent, indicating it is rich in blood vessels. C. On ADC maps derived from diffusion-weighted MR images, the tumor rim (arrowhead) exhibits a decreased ADC, indicating increased cellularity due to tumor regrowth, with an elevated ADC in the central necrotic area (n). D. MRI findings of tumor rim enlargement (arrowhead) and central necrosis (n) 12 days after treatment are confirmed in the macroscopic tumor section. E. Dynamic changes in $\mathrm{K}^{\text {trans }}$ in a liver tumor model in another rat. The tumor (arrows) exhibits an abundant blood supply with high $\mathrm{K}^{\text {trans }}$ before treatment (pre). Six hours after CA4P treatment, vascular shutdown is indicated by a low $\mathrm{K}^{\text {trans }}$ in the central region surrounded by residual tumor at the periphery with a moderate $\mathrm{K}^{\text {trans }}$. Two days after treatment, tumor recurrence is evident at the periphery with a rebounding $\mathrm{K}^{\text {trans }}$. Figure $2 \mathrm{E}$ was reprinted and adapted with permission from Wang HJ, Marchal G, Ni Y. Multiparametric MRI biomarkers for measuring vascular disrupting effect on cancer. World J Radiol. 2011; 3: 1-16. 
is species-dependent.

Mature CECs, which are usually defined phenotypically by the expression of membrane glycoprotein CD146, are a newly recognized population of non-hematopoietic cells in the blood [42]. As CEPs, they are rare in the blood of healthy individuals $(0.01 \%)$, and are derived from existing vasculature. They may be sloughed off in a wide variety of pathological conditions including inflammatory, infectious, and vascular diseases. Therefore, an increase in CECs has been reported as a biomarker for assessing vascular insult. Beaudry et al. [43] reported that mature CECs were increased in mice with Lewis lung carcinoma 3 days after treatment with a VDA (ZD6126). Beerepoot et al. [44] also observed a VDA-induced increase in CECs in a clinical study. In another study of patients with advanced solid tumors [45], 18 out of $19(95 \%)$ patients showed a significant increase in CECs 2 to 8 hours after infusion of ZD6126. $A$ rapid increase in the $\mathrm{CEC}$ level could also be induced by treatment with taxane-based chemotherapy in patients with various solid tumors. Since no changes in CEC levels were detected in non-tumor-bearing VDA-treated mice or tumor-bearing vehicle-treated mice $[8,43]$, it was suggested that the increase in CEC level was the direct consequence of irreversible VDA-induced injury to the tumor vasculature [46]. Based on these findings, Bhatt et al. [47] hypothesized that the early increase in CECs induced by VDA therapy represents a parallel increase in the number of apoptotic CECs. Despite these findings, it is not clear whether CECs may be mobilized from the bone marrow by cytokines [45] and enhance tumor angiogenesis [48].

\section{IMAGING BIOMARKERS OF TUMOR RESISTANCE TO VASCULAR DISRUPTING AGENTS}

Advances in the development of new anti-vascular therapies for solid tumors highlight the need for noninvasive imaging methods to evaluate therapeutic efficacy. Magnetic resonance imaging (MRI) is an established tool for the in vivo monitoring of anatomical and functional changes in tumors after treatment with novel molecular targeting drugs. MRI has superb soft tissue contrast, excellent temporal and spatial resolution, and is noninvasive. A multi-parametric MRI approach has been widely used to evaluate the therapeutic effects of VDAs, and typically includes the following imaging sequences: conventional anatomical imaging (i.e., T1weighted imaging [T1WI] and T2-weighted imaging [T2WI]), functional imaging such as diffusion-weighted imaging (DWI), T1-weighted dynamic contrast-enhanced MRI (DCE-MRI), T2*-weighted dynamic susceptibility contrast-enhanced MRI (DSC-MRI), and contrastenhanced T1WI (CE-T1WI). For a basic understanding of the MRI and sequences, please refer to detailed explanations elsewhere $[49,50]$.

A variety of imaging markers can be used to evaluate tumor resistance to VDAs. Although a singledose of a VDA can cause extensive central necrosis of the tumor, a small solid rim always remains in the periphery, even in the most responsive tumors [6]. In preclinical studies, the viable tumor rim appeared 2 to 3 days after CA4P or ZD6126 treatment. The initial rim is typically several millimeters in width and will grow in a centrifugal manner over time toward the necrotic area, while the tumor volume may remain unchanged. The residual rim has been histologically verified to be the regrowth of tumor cells. On MRI, an enhanced rim on CE-T1WI after intravenous injection of a contrast agent reflects the sparing of viable tumor cells.

In addition to this morphological marker, functional imaging markers can also be used to evaluate tumor resistance to VDAs. DWI is a MRI technique that can be used to quantify the mobility of water molecules in vivo. By measuring the DWI-derived apparent diffusion coefficient (ADC) of the tissue, quantitative information on the movement of water molecules can be obtained. Regrowth of tumors that are resistant to VDAs may increase the cellularity, and the interstitial pressure can also be high [51]. This results in the restricted diffusivity of water molecules and a lower ADC in tumors compared to previous values or the pretreatment ADC. Thus, a decrease in the ADC of the tumor after VDA treatment is indicative of regrowth [52].

Tumor blood vessels are immature and disorganized, often with poorly developed endothelial cell-lined basement membranes. Therefore, they have high permeability and high interstitial fluid pressure. This intrinsic feature of the tumor vascular can be evaluated using a parameter of permeability (i.e., $\mathrm{K}^{\text {trans }}$ [unit/ $\mathrm{min}$, the volume transfer constant of the contrast agent derived from DCE-MRI). An increase in $\mathrm{K}^{\text {trans }}$ can be an indicator of VDA-resistance. Increased interstitial fluid pressure can be assessed using another parameter, Ve (unit \%), the extravascular extracellular volume fraction. Additionally, blood flow in the tumor vascular network is heterogeneous, low, and can be intermittent, although the blood volume may increase with tumor regrowth.

As an example, despite the rapid disruption of tumor blood vessels and extensive necrosis after treatment with VDAs, a ring of viable tumor cells has invariably been shown to appear at the tumor periphery after 2 to 3 days in a variety of preclinical tumor models $[6,51,53-56]$. The rim becomes more significant 9 to 12 days after treatment $[12,51]$ and it can remain even after a third administration of CA4P [53]. During this process, the ADC and blood perfusion-related parameters ( $\mathrm{K}^{\text {trans }}, \mathrm{ADC}_{\text {perf }}$ initial slope) show a transient reduction from 1 to 6 hours as a result of the shutdown of blood vessels. This is followed by an increase in the ADC primarily in the center of the tumors at approximately 2 days, which is indicative of necrosis 
[51]. However, the decrease in the ADC and increase in $\mathrm{K}^{\text {trans }}$, blood flow, and blood volume at the tumor periphery from 2 to 9 or 12 days suggests the early recovery of perfusion and relapse of the tumor $[12,51]$. All of these imaging markers of tumor resistance to VDAs have been found to be consistent with tumor relapse in the periphery and confirmed by histopathological examination.

Since genotypic heterogeneity within a solid tumor can greatly influence tumor growth and therapeutic response [57], spatial heterogeneity is common between and within tumors. This prevents adequate evaluation of therapeutic effects and is a key point in tumor resistance $[58,59]$. Conventional imaging measurements using only the tumor size or average parameter values neglect the rich spatial information inherent to tumors. Additional quantitative MRI approaches have been used to overcome this problem. For instance, histogram analysis can be used to characterize and compare the distribution of tumor imaging markers by quantifying the number of pixels according to each intensity level in the entire tumor. Baek et al. [60] reported that the percent change of histogram-derived skewness and kurtosis of perfusion can be used to differentiate early tumor progression from pseudoprogression in patients with glioblastoma. In a study by Ahn et al. [61], histogram analysis of ADC maps was successfully used to differentiate histological grades of head and neck squamous cell carcinoma. The functional diffusion map (fDM) derived from DWI [62, 63], or parameter response maps (PRMs) derived from DSCMRI [64] or DCE-MRI [65], are voxel-based analytical methods that use registered functional parameter maps before and after treatment. They allow categorization of the individual tumor voxel into three groups (increased, unchanged, decreased) based on the extent of the changes in parameter values during therapy. In an animal tumor model, fDM has demonstrated the potential to detect the emergence of resistance in real-time [66]. Thus, spatially heterogeneous regions that exhibit either responsive or early emergence of VDA-resistant cell populations within a tumor can be quantified by fDM or PRM.

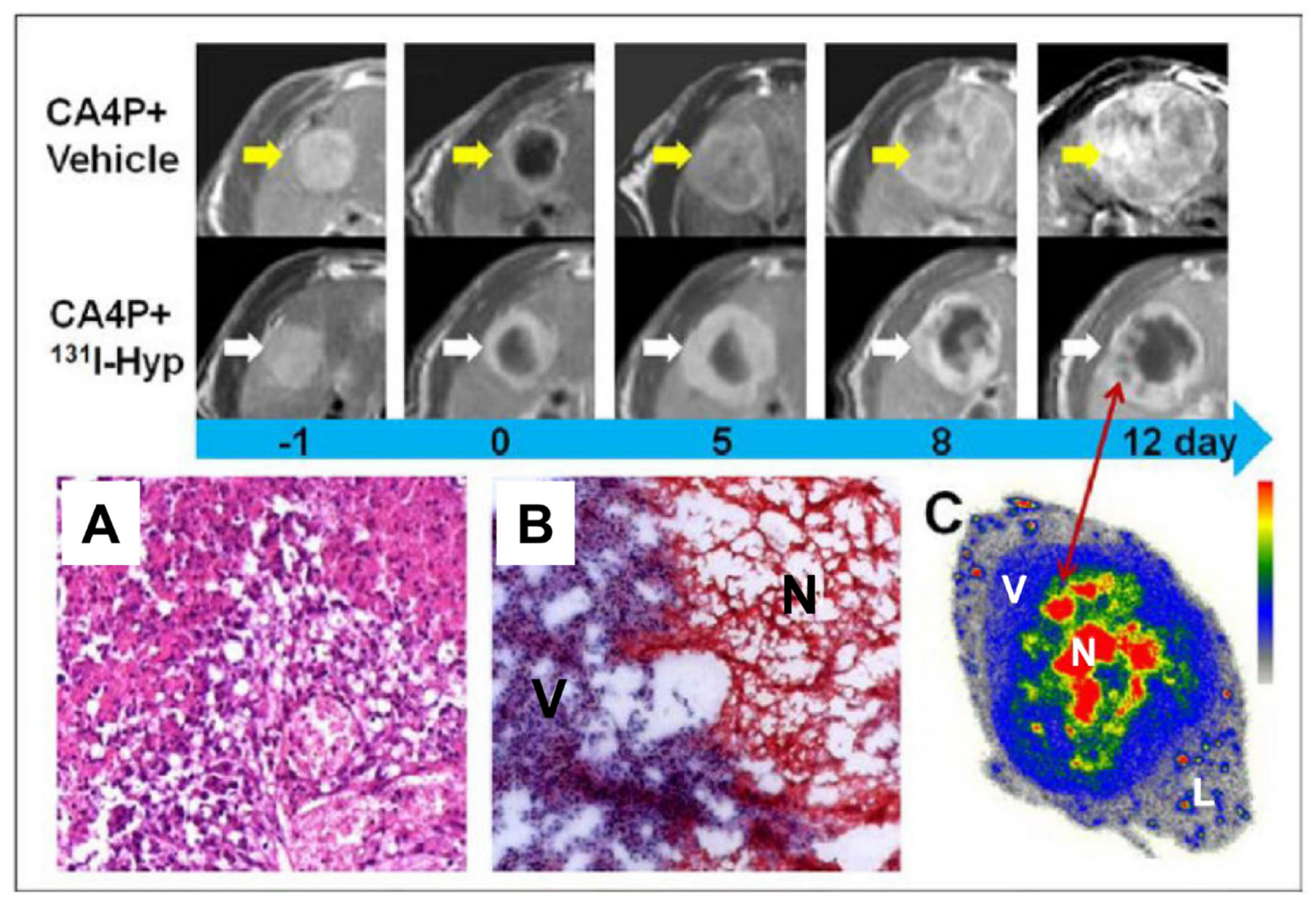

Figure 3: CA4P in combination with necrosis-targeted radiotherapy with ${ }^{131} \mathrm{I}$-Hyp-labeled hypericin. First two rows. MR images of representative tumors from the two groups show increased tumor volume as well as intratumoral necrosis. On day 0, a hyperintense rim is observed surrounding the hypointense necrotic tumor. As compared with the CA4P control group, tumor growth in the ${ }^{131}$ I-Hyp group was much slower, with intratumoral necrosis present until 12 days. A., B. Photomicrographs of $5 \mu \mathrm{m}$ tumor sections sampled from the interface between necrotic $(\mathrm{N})$ and viable tumor cells $(\mathrm{V})$. In the CA4P control group (A), viable and dead cells coexist with new vessels. Ionizing radiation of tumor cells exposed to ${ }^{131} \mathrm{I}$-Hyp causes marked cell death characterized by cell membrane damage and extensive tumor damage (B). C. Twelve days after administration of ${ }^{131} \mathrm{I}-\mathrm{Hyp}$, foci indicative of radiation-induced cell death are observed inside the viable tumor rim in MR images (red arrow), which corresponded to nests of relative high radioactivity in autoradiograms of the same sections. The liver (L) displays much lower radioactivity compared to the viable tumor $(\mathrm{V})$, and the intratumoral necrosis $(\mathrm{N})$. Reprinted with permission from Li J, Cona MM, Chen F, Feng Y, Zhou L, Yu J, Nuyts J, de Witte P, Zhang J, Himmelreich U, Verbruggen A, Ni Y. Theranostics. 2012; 2: 1010-1019. 
Table 1. Representative solutions for tumor resistance to vascular disrupting agents (VDAs)

\begin{tabular}{|c|c|c|c|c|c|c|c|}
\hline Author & Year & Subject & VDA & \begin{tabular}{|l|}
$\begin{array}{l}\text { Combination } \\
\text { therapy }\end{array}$ \\
\end{tabular} & \begin{tabular}{|l|}
$\begin{array}{l}\text { Sequence } \\
\text { therapies }\end{array}$ \\
\end{tabular} & Outcomes & Ref \\
\hline $\begin{array}{l}\text { Siemann } \\
\text { DW et al }\end{array}$ & 2004 & $\begin{array}{l}\text { nude } \\
\text { mice }\end{array}$ & ZD6126 & $\begin{array}{l}\text { Antiangiogenic agents } \\
\text { (AA): ZD6474 }\end{array}$ & $\mathrm{AA}+\mathrm{VDA}$ & $\begin{array}{ll}\text { tumor } & \text { growth } \\
\text { delay } & \\
\end{array}$ & {$[65]$} \\
\hline $\begin{array}{l}\text { Shaked Y } \\
\text { et al }\end{array}$ & 2006 & $\begin{array}{l}\text { nude } \\
\text { mice }\end{array}$ & Oxi-4503 & AA: DC101 & $\mathrm{AA}+\mathrm{VDA}$ & $\begin{array}{l}\text { reduction in tumor } \\
\text { rim and blood flow }\end{array}$ & {$[29]$} \\
\hline $\begin{array}{l}\text { Chen F et } \\
\text { al }\end{array}$ & 2012 & rat & ZD6126 & AA: Thalidomide & $\mathrm{AA}+\mathrm{VDA}$ & $\begin{array}{l}\text { reduction in } \\
\text { tumor rim and } \\
\text { hemodynamic } \\
\text { index }\end{array}$ & {$[10]$} \\
\hline $\begin{array}{l}\text { Siemann } \\
\text { DW et al }\end{array}$ & 2002 & $\begin{array}{l}\text { nude } \\
\text { mice }\end{array}$ & $\begin{array}{l}\text { DMXAA, } \\
\text { CA4P }\end{array}$ & $\begin{array}{l}\text { Chemotherapy } \\
\text { (Chem): cisplatin, } \\
\text { cyclophosphamide }\end{array}$ & Chem + VDA & $\begin{array}{l}\text { extensive } \\
\text { hemorrhagic } \\
\text { necrosis, dose } \\
\text { dependent tumor } \\
\text { cell death }\end{array}$ & {$[88]$} \\
\hline $\begin{array}{l}\text { Martinelli } \\
\text { M, et al }\end{array}$ & 2007 & $\begin{array}{l}\text { nude } \\
\text { mice }\end{array}$ & ZD6126 & Chemo: paclitaxel & VDA + Chem & $\begin{array}{l}50-57 \% \text { tumors } \\
\text { regressing }\end{array}$ & {$[92]$} \\
\hline $\begin{array}{l}\text { Daenen } \\
\text { LG et al }\end{array}$ & 2009 & $\begin{array}{l}\text { nude \& } \\
\text { SCID } \\
\text { mice }\end{array}$ & OXi4503 & $\begin{array}{l}\text { Chemo: } \\
\text { dose mow- } \\
\text { cyclophosphamide }\end{array}$ & Chem + VDA & $\begin{array}{l}\text { decrease of tumor } \\
\text { rim and marked } \\
\text { suppression of } \\
\text { tumor growth }\end{array}$ & {$[71]$} \\
\hline Li J et al & 1998 & mice & CA4P & Radiotherapy (Radio) & Radio + VDA & $\begin{array}{l}\text { enhancements in } \\
\text { tumor cell killing } \\
\& \text { antitumor } \\
\text { effects } \\
\text { radiotherapy } \\
\end{array}$ & {$[100]$} \\
\hline $\begin{array}{l}\text { Murata R } \\
\text { et al }\end{array}$ & 2001 & mice & DMXAA & Radio & Radio + VDA & $\begin{array}{l}\text { enhancement of } \\
\text { tumor radiation } \\
\text { damage }\end{array}$ & {$[91]$} \\
\hline $\begin{array}{l}\mathrm{Ng} \text { QS et } \\
\text { al }\end{array}$ & 2012 & $\begin{array}{l}\text { phase Ib } \\
\text { trial in } \\
\text { NSCLC } \\
\text { patients }\end{array}$ & CA4P & Radio & Radio + VDA & $\begin{array}{l}\text { well tolerated in } \\
\text { most patients; } 7 \\
\text { responses out of } \\
18 \text { patients } \\
\end{array}$ & {$[72]$} \\
\hline $\begin{array}{l}\text { Iversen } \\
\text { AB et al }\end{array}$ & 2013 & mice & $\begin{array}{l}\text { DMXAA } \\
\text { CA4P } \\
\text { OXi4503 }\end{array}$ & $\begin{array}{l}\text { Radio: single or } \\
\text { fractionated radiation }\end{array}$ & $\begin{array}{l}\text { Radio + VDA } \\
\text { VDA + Radio }\end{array}$ & $\begin{array}{l}\text { increased } \\
\text { antitumor effects; } \\
\text { increased response } \\
\text { only seen in } \\
\text { OXi4503 } \\
\end{array}$ & {$[101]$} \\
\hline $\begin{array}{l}\text { Pedley } \\
\text { RB et al }\end{array}$ & 2001 & $\begin{array}{l}\text { nude } \\
\text { mice }\end{array}$ & CA4P & \begin{tabular}{|l|} 
Radioimmuno- \\
Therapy (RIT): ${ }^{131} \mathrm{I}$ \\
labled-antibody- \\
targeted \\
\end{tabular} & $\mathrm{RIT}+\mathrm{VDA}$ & $\begin{array}{l}\text { complete tumor } \\
\text { cures in five of six } \\
\text { mice }\end{array}$ & {$[74]$} \\
\hline $\begin{array}{l}\text { Meyer } \mathrm{T} \\
\text { et al }\end{array}$ & 2009 & $\begin{array}{l}\text { phase I } \\
\text { trial in } \\
\text { advanced } \\
\text { cancers }\end{array}$ & CA4P & $\begin{array}{l}\text { RIT: }{ }^{131} \mathrm{I} \quad \text { labled- } \\
\text { antibody-targeted }\end{array}$ & RIT + VDA & $\begin{array}{l}\text { a partial response } \\
\text { shown in one out } \\
\text { of ten patients }\end{array}$ & {$[73]$} \\
\hline Li J et al & 2011 & rat & CA4P & $\begin{array}{l}{ }^{131} \mathrm{I} \text { labled necrosis } \\
\text { targeting hypericin }\left({ }^{131} \mathrm{I}\right. \\
\text {-hypericin) }\end{array}$ & $\underset{\text { VDA }}{{ }^{131} \text { I-hypericin }}+$ & \begin{tabular}{|l|} 
kill of residual \\
tumor cells \& \\
inhibited tumor \\
regrowth
\end{tabular} & {$[78]$} \\
\hline $\begin{array}{l}\text { Shao } \mathrm{H} \text { et } \\
\text { al }\end{array}$ & 2015 & rabbit & CA4P & ${ }^{131} \mathrm{I}$-hypericin & $\underset{\text { VDA }}{{ }^{131} \text { I-hypericin }}+$ & $\begin{array}{lr}\text { well } & \text { inhibited } \\
\text { viable } & \text { tumor rims } \\
\& & \text { prolonged } \\
\text { tumor } & \text { doubling } \\
\text { time } & \\
\end{array}$ & {$[80]$} \\
\hline
\end{tabular}




\section{SOLUTIONS FOR TUMOR RESISTANCE TO VASCULAR DISRUPTING AGENTS}

More potent VDAs have been developed to increase the therapeutic efficacy. For example, CA1P, a second-generation small molecule derivative of CA4P, has been shown to induce a smaller viable tumor rim. Another synthetic CA4P derivative, AVE8062, has also demonstrated enhanced antitumor activity by more substantially decreasing tumor blood flow [6, 67, 68]. Many strategies have been proposed to improve VDA effectiveness. Current efforts have predominantly involved combining VDAs with other approaches such as antiangiogenic agents [12, 32, 68-71], conventional chemotherapy [72-75], radiotherapy [67, 76], radioimmunotherapy [77-79], or dual-targeting therapy [80-84].

\section{Vascular disrupting agents combined with antiangiogenic agents}

In theory, VDAs and antiangiogenic agents should act synergistically because VDAs induce acute vascular shutdown and antiangiogenic agents inhibit the growth of new tumor vessels. Many studies have confirmed this hypothesis. Siemann et al. [69] treated human renal cell carcinoma and Kaposi's sarcoma in mice with a combination of ZD6126 (vascular disrupting) and ZD6474 (antiangiogenic). The combined therapy resulted in a remarkable delay in tumor growth compared to either agent alone. Additionally, Shaked et al. [32] treated tumor-bearing mice with DC101, an antiangiogenic agent, followed by OXi-4503, a VDA, and observed a significant reduction in tumor rim size and blood flow. This was a result of the suppression of CEP levels and mobilization by $\mathrm{DC} 101$ [85], which would otherwise home to the viable tumor rim and contribute to angiogenesis. In a rodent liver tumor model, Chen et al. [12] studied combined treatment with ZD6126 and thalidomide, an antiangiogenic agent [86]. They observed cumulative tumor apoptosis or necrosis, and consequently a decrease in the viable tumor rim. The combined approach also prolonged the duration of the reduction in $\mathrm{K}^{\text {trans }}$ in the tumor, and improved the hemodynamic index. This was most likely a result of the transient normalization of tumor vessels [87] induced by thalidomide. However, Chen et al. did not observe acute mobilization of CEPs after ZD6126 treatment [10].

An increase in CECs can result from a direct vascular insult, and a VDA-induced rise in CECs has been observed in both an animal study [43] and in a clinical trial [44]. However, the combined use of an antiangiogenic agent with a VDA did not suppress CEC levels. Instead, CEC levels could increase [47], although the rapid rise in CEPs could be blocked [32]. Thus, both CECs and CEPs may be used to monitor the therapeutic effects of anti- vascular treatments.

\section{Vascular disrupting agents combined with chemotherapy}

Based on experimental observations, VDAs and chemotherapeutic agents can be categorized as microtubule-binding agents, and differences in therapeutic effects mainly depend on their tubulin binding sites and the duration of binding. For instance, most VDAs reversibly bind to the colchicine site of tubulin, whereas vinblastine and paclitaxel bind to the vinca alkaloid and taxane sites, respectively, and result in persistent inhibition of mitotic processes and proliferation [67].

Several mechanisms have been proposed to justify the combined regimen of a VDA and chemotherapy. First, because VDAs and cytotoxic agents target different components of tumors (i.e., the tumor vasculature and proliferating tumor cells, respectively), complementary benefits are possible [73]. In a Calu-6 model, ZD6126 combined with cisplatin resulted in enhanced delay of tumor growth [72]. A CA4 derivative, AVE8062, in combination with docetaxel significantly inhibited the growth of chemotherapy-resistant ovarian cancers and prolonged survival in HeyA8-injected mice [88]. The combination of CA4P with liposomal doxorubicin resulted in the greatest delay in tumor growth in a B16-F10 murine melanoma model [74].

Second, the mobilization of BM-derived CEPs may contribute to vasculogenesis. Some chemotherapy drugs can inhibit VDA-induced mobilization of BM-derived CEPs $[35,89]$. Thus, combining these drugs with VDAs may amplify the antitumor effects of VDAs. For example, administration of cyclophosphamide (CTX) on a regular low-dose metronomic schedule resulted in a consistent decrease in both the level and viability of CEPs, and enhanced inhibition of tumor growth in human lymphomabearing mice [90]. When the VDA OXi4503 was combined with CTX to treat primary orthotopic tumors in mice in a metronomic manner, a reduction of the residual rim and enhanced inhibition of tumor growth was observed due to the suppression of the CEP spike and tumor colonization induced by OXi4503 [75]. Furthermore, low-dose metronomic chemotherapy could induce a transient normalization of functional tumor vessels [87] that may improve the delivery of chemotherapeutic agents. However, only certain chemotherapeutic agents such as CTX and gemcitabine can suppress the mobilization and increase in CEPs [35]. Other agents including paclitaxel, docetaxel, and 5-fluorouracil do not inhibit CEP mobilization but can induce a rapid increase in CEPs shortly after treatment [35].

Third, the synergistic effect generated by combining VDAs and chemotherapeutic agents can be affected by the schedule and sequence of administration of the two agents. 
Theoretically, chemotherapy should be administered before the VDA. This would allow the cytotoxic drug to be well distributed throughout the tumor through the vasculature, and then trapped once the blood vessels are shutdown by the VDA $[9,91]$. Maximum effects were achieved when cisplatin was administered 1 to 3 hours before the administration of a VDA [92]. Complications can results if a VDA is administered before chemotherapy. For example, Siemann et al. [92] reported impaired treatment efficacy when cisplatin was administered 1 hour after CA4P or 2 hours after DMXAA in a rodent KHT sarcoma tumor model. This may be explained by the fact that cisplatin delivery to the tumor may be impeded shortly after VDA-induced vessel shutdown, and some tumor cells may survive under hypoxic conditions after VDA treatment [93-95]. However, an enhanced antitumor effect, and even complete tumor remission, was achieved when paclitaxel was administered 24 hours after ZD6126 [96]. This relatively long interval may provide additional time for the tumor to develop VDA-induced central necrosis. Cytotoxic drugs can then be used to target the proliferating cells in the residual viable rim [73, 97-99]. Thus, pretreatment with a VDA may amplify the effects of cytotoxic agents on proliferating cells in the tumor periphery [91].

\section{Vascular disrupting agents combined with radiotherapy}

Only a few clinical trials have evaluated the combination of VDAs with radiotherapy [76, 77], though preclinical studies have demonstrated the effectiveness of combination treatment for solid tumors [67]. The resistance of solid tumors to VDAs is primarily the result of residual viable cells in the periphery. These viable cells are likely to be in a well-oxygenated environment and actively proliferating, which makes them more sensitive to radiotherapy $[69,79,100-103]$. In addition, tumor cells in the $\mathrm{G} 2 / \mathrm{M}$ phase of the cell cycle are more sensitive to radiotherapy, and VDAs can induce tumor cell arrest in the G2/M phase [67].

Treatment with VDAs can induce central necrosis. Thus, regions of hypoxia and acidosis develop within the tumor. Because oxygen is critical for effective radiationinduced DNA damage, hypoxia and acidosis may impair the effects of radiotherapy on tumors [67]. Therefore, it is generally optimal to perform radiotherapy before administering a VDA [67]. The first report of such a combination by Li et al. [104] showed additive effects in a murine tumor model. An enhanced antitumor effect has been observed with a range of VDAs (DMXAA, CA4P and OXi4503) combined with single or fractionated irradiation in a $\mathrm{C} 3 \mathrm{H}$ murine mammary carcinoma model [105]. Indeed, some studies have confirmed a reduced effect when VDAs were administered prior to irradiation [95]. However, there are some exceptions. For instance, OXi4503 or ZD6126 yielded an increased response when administered before radiotherapy [105, 106]. In KHT sarcomas, an improved antitumor effect was observed whether ZD6126 was administered before or after radiotherapy [92, 106, 107]. The discrepancy in therapeutic responses may be related to the different VDAs and different tumor models used in these studies [99].

Interestingly, combination therapy has been particularly effective for the treatment of large tumors, which are normally less sensitive to radiotherapy due to hypoxia and acidosis caused by increased interstitial pressure and impaired blood flow $[67,107,108]$. However, VDAs cause extensive central necrosis in tumors and allow elimination of residual rim cells with radiotherapy [9].

\section{Vascular disrupting agents combined with targeting molecules labeled with ${ }^{131}$ iodine}

Two strategies for combining VDAs with targeted internal irradiation have been pursued, in light of tumor resistance to VDAs and the limited efficacy of radioimmunotherapy for the treatment of solid tumors (due to poor penetration into the central regions of large tumors) and the relative resistance of hypoxic tissue to radiotherapy) [67].

\section{VASCULAR DISRUPTING AGENTS IN COMBINATION WITH RADIOIMMUNOTHERAPY}

The combination of VDAs and radioimmunotherapy has been evaluated using a carcinoembryonic antigen (CEA)-positive colorectal xenograft model [78]. The study showed that the combination of the ${ }^{131} \mathrm{I}-\mathrm{A} 5 \mathrm{~B} 7$ anti-CEA antibody with CA4P eliminated five of six tumors. In another animal experiment, the retention of the ${ }^{131}$ I-A5B7 anti-CEA antibody was extended for up to 4 days in an SW1222 colorectal xenograft when CA-4P was administered 2 days after the antibody [109]. Based on these preclinical studies, a phase I clinical trial was performed using the same combination strategy (i.e., ${ }^{131}$ I-A5B7 anti-CEA antibody and CA4P) in patients with gastrointestinal adenocarcinoma [77]. However, only one of 10 patients showed a partial response. Although tumor-specific uptake of ${ }^{131} \mathrm{I}-\mathrm{A} 5 \mathrm{~B} 7$ was demonstrated, no direct comparison of the absorbed doses between the target organs and the tumor was provided. In addition, dose-limiting myelosuppression was observed in heavily pretreated patients. 


\section{VASCULAR DISRUPTING AGENTS IN COMBINATION WITH A NECROSIS- TARGETING MOLECULE LABELED WITH ${ }^{131}$ IODINE}

Recently, a specific antitumor approach has been proposed that involves combining a natural necrosistargeting molecule labeled with ${ }^{131}$ iodine with CA4P [82]. Hypericin, a polycyclic aromatic compound, is a naturally occurring chromophore extracted from the plant genus Hypericum perforatum commonly known as St. John's Wort [110]. Hypericin has been used extensively in photodynamic therapy as a potent photosensitizer due to its high photo-oxidative cellular damaging effect [111-113]. However, the applications are limited to only superficial tumors because the toxic functions must be activated by an external light source.

More recently, Ni and colleagues [114-118] discovered that hypericin has a strong necrosis affinity. Although the mechanism responsible for the necrosisavid effect has not been fully elucidated, one possibility is that hypericin may bind to phosphatidylserine and phosphatidylethanolamine in the lipid bilayer of the cell $[83,119]$. The necrosis-avid feature of hypericin is independent of its photosensitivity. In addition, a series of radiolabeled hypericin derivatives such as ${ }^{123}$-iodohypericine and ${ }^{131}$ I-iodohypericine have shown a similar necrosis affinity in several infarction and intratumoral necrosis animal models [114-117]. Therefore, there has been increasing interest in hypericin as a potential necrosis-targeting therapy. Van de Putte et al. [114] verified the necrosis avidity of hypericin and the radiotherapeutic effect of ${ }^{131}$ I-hypericin in nude mice bearing radiation-induced fibrosarcoma (RIF-1). Significant delays in tumor growth were observed in the fluorodeoxyglucose micro-positron emission tomography group compared to the control group.

$\mathrm{Ni}$ et al. [80-82] took advantage of the necrosisavid feature of hypericin and designed a novel anticancer theranostic strategy that combined a VDA (CA4P) and ${ }^{131}$ I labeled hypericin $\left({ }^{131} \mathrm{I}-\mathrm{Hyp}\right)$. In this sequential dualtargeting approach, a VDA is used to disrupt the tumor vessels (the first target) in solid tumors and cause massive necrosis. Following VDA treatment, ${ }^{131} \mathrm{I}$-hypericin is injected intravenously and reaches the necrotic zone based on its strong necrosis avidity. Accumulated ${ }^{131}$ I-hypericin in CA4P-induced necrotic zones may kill residual cancer cells (the second target) with ionizing radiation and significantly inhibit tumor relapse. The necrotic avidity of ${ }^{131}$ I-hypericin was remarkable, with a necrotic target-toliver ratio of more than 20 times, which was approximately 100 times the cumulative dose of 50 Gy that is necessary to elicit a tumor response to radiotherapy. More recently, ${ }^{131}$ I-hypericin was administered 24 hours after CA4P in a rabbit model of multifocal VX2 tumors [84]. The results demonstrated the high targetability of ${ }^{131}$ I-hypericin to tumor necrosis by in vivo single-photon emission computed tomography. The accumulation of ${ }^{131}$ I-hypericin was 98 times higher in necrotic tumor areas compared to viable tumors and other organs by gamma counting, and was confirmed by autoradiography and fluorescence microscopy. The necrosis-targeting effect persisted for more than 9 days. Tumor growth was significantly reduced and the doubling time was significantly increased in response to combined VDA ${ }^{131}$ I-hypericin treatment.

Given that necrosis is common in solid tumors treated with anticancer therapies, this sequential dualtargeting approach may be a novel solution to the problem of tumor resistance to VDA therapy. Another advantage of this strategy is that the residual viable tumor cells following VDA treatment may not only be eradicated, but also can be visualized with nuclear imaging modalities as radiolabeled hypericin, which exhibits superb sensitivity in targeting necrotic tissues [114].

\section{SUMMARY}

In summary, preclinical studies and clinical trials have demonstrated the existence of a residual viable tumor rim after treatment of solid tumors with VDAs. Thus, tumor cells may survive despite vascular disruption and recur, which is suggestive of tumor resistance to these therapeutic agents. Although several mechanisms have been proposed to explain tumor resistance, none of them can explain the entire phenomenon. A variety of MRI markers, particularly functional parameters, can be obtained to visualize and quantify the process of tumor resistance. Many efforts have been made to improve the antitumor effects of VDAs. Current strategies to prevent tumor resistance mainly emphasize the combination of VDAs with other approaches including antiangiogenic agents, chemotherapy, radiotherapy, radioimmunotherapy, and sequential dual-targeting internal radiotherapy. Most of these combination therapies have demonstrated promising effects towards combating the residual viable tumor rim. However, much work remains before they can be incorporated into routine clinic practice.

\section{ACKNOWLEDGMENTS}

This work was partly supported by the National Natural Science Foundation of China (NSFC) project 30670603 and the Health and Family Planning Commission of the Zhejiang Province of China project 2014PYA009.

\section{CONFLICTS OF INTEREST}

The authors declare no relevant competing financial interests to disclose 


\section{REFERENCES}

1. Heath VL, Bicknell R. Anticancer strategies involving the vasculature. Nat Rev Clin Oncol. 2009; 6: 395-404.

2. Denekamp J, Hobson B. Endothelial-cell proliferation in experimental tumours. Br J Cancer. 1982; 46: 711-20.

3. Folkman J. Angiogenesis in cancer, vascular, rheumatoid and other disease. Nat Med. 1995; 1: 27-31.

4. Blagosklonny MV. How Avastin potentiates chemotherapeutic drugs: action and reaction in antiangiogenic therapy. Cancer biology \& therapy. 2005; 4: 1307-10.

5. Blagosklonny MV. Antiangiogenic therapy and tumor progression. Cancer Cell. 2004; 5: 13-7.

6. Tozer GM, Kanthou C, Baguley BC. Disrupting tumour blood vessels. Nat Rev Cancer. 2005; 5: 423-35.

7. Tozer GM, Prise VE, Wilson J, Cemazar M, Shan S, Dewhirst MW, Barber PR, Vojnovic B, Chaplin DJ. Mechanisms associated with tumor vascular shut-down induced by combretastatin A-4 phosphate: intravital microscopy and measurement of vascular permeability. Cancer Res. 2001; 61: 6413-22.

8. Taylor M, Billiot F, Marty V, Rouffiac V, Cohen P, Tournay E, Opolon P, Louache F, Vassal G, Laplace-Builhe C, Vielh P, Soria JC, Farace F. Reversing resistance to vascular-disrupting agents by blocking late mobilization of circulating endothelial progenitor cells. Cancer discovery. 2012; 2: 434-49.

9. Wu XY, Ma W, Gurung K, Guo CH. Mechanisms of tumor resistance to small-molecule vascular disrupting agents: treatment and rationale of combination therapy. Journal of the Formosan Medical Association. 2013; 112: 115-24.

10. Horsman MR, Ehrnrooth E, Ladekarl M, Overgaard J. The effect of combretastatin A-4 disodium phosphate in a $\mathrm{C} 3 \mathrm{H}$ mouse mammary carcinoma and a variety of murine spontaneous tumors. Int J Radiat Oncol Biol Phys. 1998; 42: 895-8.

11. El-Emir E, Boxer GM, Petrie IA, Boden RW, Dearling JL, Begent RH, Pedley RB. Tumour parameters affected by combretastatin A-4 phosphate therapy in a human colorectal xenograft model in nude mice. Eur J Cancer. 2005; 41: 799806.

12. Chen F, Feng Y, Zheng K, De Keyzer F, Li J, Cona MM, Wang H, Jiang Y, Yu J, Marchal G, Verfaillie C, De Geest B, Oyen R, Ni Y. Enhanced antitumor efficacy of a vascular disrupting agent combined with an antiangiogenic in a rat liver tumor model evaluated by multiparametric MRI. PLoS One. 2012; 7: e41140.

13. Pugh CW, Ratcliffe PJ. Regulation of angiogenesis by hypoxia: role of the HIF system. Nat Med. 2003; 9: 677-84.

14. Sheng Y, Hua J, Pinney KG, Garner CM, Kane RR, Prezioso JA, Chaplin DJ, Edvardsen K. Combretastatin family member OXI4503 induces tumor vascular collapse through the induction of endothelial apoptosis. Int J Cancer.
2004; 111: 604-10.

15. Boehle AS, Sipos B, Kliche U, Kalthoff H, Dohrmann P. Combretastatin A-4 prodrug inhibits growth of human nonsmall cell lung cancer in a murine xenotransplant model. The Annals of thoracic surgery. 2001; 71: 1657-65.

16. Brasch RC, Li KC, Husband JE, Keogan MT, Neeman M, Padhani AR, Shames D, Turetschek K. In vivo monitoring of tumor angiogenesis with MR imaging. Acad Radiol. 2000; 7: 812-23.

17. Blagosklonny MV. Hypoxia-inducible factor: Achilles' heel of antiangiogenic cancer therapy (review). International journal of oncology. 2001; 19: 257-62.

18. Minardi D, Lucarini G, Filosa A, Milanese G, Zizzi A, Di Primio R, Montironi R, Muzzonigro G. Prognostic role of tumor necrosis, microvessel density, vascular endothelial growth factor and hypoxia inducible factor-1alpha in patients with clear cell renal carcinoma after radical nephrectomy in a long term follow-up. International journal of immunopathology and pharmacology. 2008; 21: 447-55.

19. Ruan K, Song G, Ouyang G. Role of hypoxia in the hallmarks of human cancer. Journal of cellular biochemistry. 2009; 107: 1053-62.

20. Schelter F, Gerg M, Halbgewachs B, Schaten S, Gorlach A, Schrotzlmair F, Kruger A. Identification of a survivalindependent metastasis-enhancing role of hypoxia-inducible factor-1alpha with a hypoxia-tolerant tumor cell line. The Journal of biological chemistry. 2010; 285: 26182-9.

21. Arvidsson Y, Bergstrom A, Arvidsson L, Kristiansson E, Ahlman H, Nilsson O. Hypoxia stimulates CXCR4 signalling in ileal carcinoids. Endocrine-related cancer. 2010; 17: 303-16.

22. Cronin PA, Wang JH, Redmond HP. Hypoxia increases the metastatic ability of breast cancer cells via upregulation of CXCR4. BMC Cancer. 2010; 10: 225.

23. Guo M, Cai C, Zhao G, Qiu X, Zhao H, Ma Q, Tian L, Li X, $\mathrm{Hu}$ Y, Liao B, Ma B, Fan Q. Hypoxia promotes migration and induces CXCR4 expression via HIF-1alpha activation in human osteosarcoma. PLoS One. 2014; 9: e90518.

24. Welford AF, Biziato D, Coffelt SB, Nucera S, Fisher M, Pucci F, Di Serio C, Naldini L, De Palma M, Tozer GM, Lewis CE. TIE2-expressing macrophages limit the therapeutic efficacy of the vascular-disrupting agent combretastatin A4 phosphate in mice. The Journal of clinical investigation. 2011; 121: 1969-73.

25. Squadrito ML, De Palma M. Macrophage regulation of tumor angiogenesis: implications for cancer therapy. Molecular aspects of medicine. 2011; 32: 123-45.

26. Lin EY, Pollard JW. Tumor-associated macrophages press the angiogenic switch in breast cancer. Cancer Res. 2007; 67: 5064-6.

27. Jassar AS, Suzuki E, Kapoor V, Sun J, Silverberg MB, Cheung L, Burdick MD, Strieter RM, Ching LM, Kaiser LR, Albelda SM. Activation of tumor-associated macrophages by the vascular disrupting agent 5,6-dimethylxanthenone- 
4-acetic acid induces an effective CD8+ T-cell-mediated antitumor immune response in murine models of lung cancer and mesothelioma. Cancer Res. 2005; 65: 11752-61.

28. Wallace A, LaRosa DF, Kapoor V, Sun J, Cheng G, Jassar A, Blouin A, Ching LM, Albelda SM. The vascular disrupting agent, DMXAA, directly activates dendritic cells through a MyD88-independent mechanism and generates antitumor cytotoxic T lymphocytes. Cancer Res. 2007; 67: 7011-9.

29. Werner N, Nickenig G. Endothelial progenitor cells in health and atherosclerotic disease. Annals of medicine. 2007; 39: 82-90.

30. Gao D, Nolan DJ, Mellick AS, Bambino K, McDonnell K, Mittal V. Endothelial progenitor cells control the angiogenic switch in mouse lung metastasis. Science (New York, NY). 2008; 319: 195-8.

31. Ribatti D. The involvement of endothelial progenitor cells in tumor angiogenesis. Journal of cellular and molecular medicine. 2004; 8: 294-300.

32. Shaked Y, Ciarrocchi A, Franco M, Lee CR, Man S, Cheung AM, Hicklin DJ, Chaplin D, Foster FS, Benezra R, Kerbel RS. Therapy-induced acute recruitment of circulating endothelial progenitor cells to tumors. Science. 2006; 313: 1785-7.

33. Farace F, Massard C, Borghi E, Bidart JM, Soria JC. Vascular disrupting therapy-induced mobilization of circulating endothelial progenitor cells. Annals of oncology. 2007; 18: 1421-2.

34. Madlambayan GJ, Butler JM, Hosaka K, Jorgensen M, Fu D, Guthrie SM, Shenoy AK, Brank A, Russell KJ, Otero J, Siemann DW, Scott EW, Cogle CR. Bone marrow stem and progenitor cell contribution to neovasculogenesis is dependent on model system with SDF-1 as a permissive trigger. Blood. 2009; 114: 4310-9.

35. Shaked Y, Henke E, Roodhart JM, Mancuso P, Langenberg MH, Colleoni M, Daenen LG, Man S, Xu P, Emmenegger U, Tang T, Zhu Z, Witte L, Strieter RM, Bertolini F, Voest EE, Benezra R, Kerbel RS. Rapid chemotherapy-induced acute endothelial progenitor cell mobilization: implications for antiangiogenic drugs as chemosensitizing agents. Cancer Cell. 2008; 14: 263-73.

36. Heissig B, Hattori K, Dias S, Friedrich M, Ferris B, Hackett NR, Crystal RG, Besmer P, Lyden D, Moore MA, Werb Z, Rafii S. Recruitment of stem and progenitor cells from the bone marrow niche requires MMP-9 mediated release of kit-ligand. Cell. 2002; 109: 625-37.

37. Du R, Lu KV, Petritsch C, Liu P, Ganss R, Passegue E, Song H, Vandenberg S, Johnson RS, Werb Z, Bergers G. HIF1alpha induces the recruitment of bone marrow-derived vascular modulatory cells to regulate tumor angiogenesis and invasion. Cancer Cell. 2008; 13: 206-20.

38. De Palma M, Nucera S. Circulating endothelial progenitors and tumor resistance to vascular-targeting therapies. Cancer discovery. 2012; 2: 395-7.
39. Purhonen S, Palm J, Rossi D, Kaskenpaa N, Rajantie I, Yla-Herttuala S, Alitalo K, Weissman IL, Salven P. Bone marrow-derived circulating endothelial precursors do not contribute to vascular endothelium and are not needed for tumor growth. Proc Natl Acad Sci U S A. 2008; 105: 66205.

40. Ziegelhoeffer T, Fernandez B, Kostin S, Heil M, Voswinckel R, Helisch A, Schaper W. Bone marrowderived cells do not incorporate into the adult growing vasculature. Circulation research. 2004; 94: 230-8.

41. Gothert JR, Gustin SE, van Eekelen JA, Schmidt U, Hall MA, Jane SM, Green AR, Gottgens B, Izon DJ, Begley CG. Genetically tagging endothelial cells in vivo: bone marrowderived cells do not contribute to tumor endothelium. Blood. 2004; 104: 1769-77.

42. Dignat-George F, Sabatier F, Blann A, Woywodt A. Detection of circulating endothelial cells: CD146-based magnetic separation enrichment or flow cytometric assay? J Clin Oncol. 2007; 25: e1-2; author reply e3-5.

43. Beaudry P, Force J, Naumov GN, Wang A, Baker CH, Ryan A, Soker S, Johnson BE, Folkman J, Heymach JV. Differential effects of vascular endothelial growth factor receptor-2 inhibitor ZD6474 on circulating endothelial progenitors and mature circulating endothelial cells: implications for use as a surrogate marker of antiangiogenic activity. Clin Cancer Res. 2005; 11: 3514-22.

44. Beerepoot LV, Radema SA, Witteveen EO, Thomas T, Wheeler C, Kempin S, Voest EE. Phase I clinical evaluation of weekly administration of the novel vascular-targeting agent, ZD6126, in patients with solid tumors. J Clin Oncol. 2006; 24: 1491-8.

45. Beerepoot LV, Mehra N, Vermaat JS, Zonnenberg BA, Gebbink MF, Voest EE. Increased levels of viable circulating endothelial cells are an indicator of progressive disease in cancer patients. Annals of oncology. 2004; 15: 139-45.

46. Blann AD, Woywodt A, Bertolini F, Bull TM, Buyon JP, Clancy RM, Haubitz M, Hebbel RP, Lip GY, Mancuso P, Sampol J, Solovey A, Dignat-George F. Circulating endothelial cells. Biomarker of vascular disease. Thrombosis and haemostasis. 2005; 93: 228-35.

47. Bhatt RS, Seth P, Sukhatme VP. Biomarkers for monitoring antiangiogenic therapy. Clin Cancer Res. 2007; 13: 777s-80s.

48. Ingram DA, Caplice NM, Yoder MC. Unresolved questions, changing definitions, and novel paradigms for defining endothelial progenitor cells. Blood. 2005; 106: 1525-31.

49. Chen F, De Keyzer F, Ni Y: Cancer Models Multiparametric Applications of Clinical MRI in Rodent Hepatic Tumor Model. In vivo MR Imaging: Methods and Protocols. Edited by Schroeder L, Faber C. Berlin: Humana Press (part of the Springer publishing group), 2011. pp. 489-507.

50. Loffroy R, Chevallier O, Moulin M, Favelier S, Genson 
P-Y, Pottecher P, Crehange G, Cochet A, Cormier L. Current role of multiparametric magnetic resonance imaging for prostate cancer. Quantitative Imaging in Medicine and Surgery. 2015; 5: 754-64.

51. Thoeny HC, De Keyzer F, Chen F, Ni Y, Landuyt W, Verbeken EK, Bosmans H, Marchal G, Hermans R. Diffusion-weighted MR imaging in monitoring the effect of a vascular targeting agent on rhabdomyosarcoma in rats. Radiology. 2005; 234: 756-64.

52. Chilla GS, Tan $\mathrm{CH}, \mathrm{Xu} \mathrm{C}$, Poh CL. Diffusion weighted magnetic resonance imaging and its recent trend - a survey. Quantitative Imaging in Medicine and Surgery. 2015; 5: 407-22.

53. Thoeny HC, De Keyzer F, Chen F, Vandecaveye V, Verbeken EK, Ahmed B, Sun X, Ni Y, Bosmans H, Hermans R, van Oosterom A, Marchal G, Landuyt W. Diffusion-weighted magnetic resonance imaging allows noninvasive in vivo monitoring of the effects of combretastatin a-4 phosphate after repeated administration. Neoplasia. 2005; 7: 779-87.

54. Thoeny HC, De Keyzer F, Vandecaveye V, Chen F, Sun X, Bosmans H, Hermans R, Verbeken EK, Boesch C, Marchal G, Landuyt W, Ni Y. Effect of vascular targeting agent in rat tumor model: dynamic contrast-enhanced versus diffusion-weighted MR imaging. Radiology. 2005; 237: 492-9.

55. Wang H, Sun X, Chen F, De Keyzer F, Yu J, Landuyt W, Vandecaveye V, Peeters R, Bosmans H, Hermans R, Marchal G, Ni Y. Treatment of rodent liver tumor with combretastatin a4 phosphate: noninvasive therapeutic evaluation using multiparametric magnetic resonance imaging in correlation with microangiography and histology. Invest Radiol. 2009; 44: 44-53.

56. Siemann DW, Chaplin DJ, Horsman MR. Vasculartargeting therapies for treatment of malignant disease. Cancer. 2004; 100: 2491-9.

57. Rehemtulla A. Overcoming intratumor heterogeneity of polygenic cancer drug resistance with improved biomarker integration. Neoplasia. 2012; 14: 1278-89.

58. Meacham CE, Morrison SJ. Tumour heterogeneity and cancer cell plasticity. Nature. 2013; 501: 328-37.

59. Gerashchenko TS, Denisov EV, Litviakov NV, Zavyalova MV, Vtorushin SV, Tsyganov MM, Perelmuter VM, Cherdyntseva NV. Intratumor heterogeneity: nature and biological significance. Biochemistry Biokhimiia. 2013; 78: $1201-15$.

60. Baek HJ, Kim HS, Kim N, Choi YJ, Kim YJ. Percent change of perfusion skewness and kurtosis: a potential imaging biomarker for early treatment response in patients with newly diagnosed glioblastomas. Radiology. 2012; 264: 834-43.

61. Ahn SJ, Choi SH, Kim YJ, Kim KG, Sohn CH, Han MH, Chang KH, Min HS. Histogram analysis of apparent diffusion coefficient map of standard and high B-value diffusion MR imaging in head and neck squamous cell carcinoma: a correlation study with histological grade. Acad Radiol. 2012; 19: 1233-40.

62. Hamstra DA, Chenevert TL, Moffat BA, Johnson TD, Meyer CR, Mukherji SK, Quint DJ, Gebarski SS, Fan X, Tsien CI, Lawrence TS, Junck L, Rehemtulla A, Ross BD. Evaluation of the functional diffusion map as an early biomarker of time-to-progression and overall survival in high-grade glioma. Proc Natl Acad Sci U S A. 2005; 102: 16759-64.

63. Moffat BA, Chenevert TL, Lawrence TS, Meyer CR, Johnson TD, Dong Q, Tsien C, Mukherji S, Quint DJ, Gebarski SS, Robertson PL, Junck LR, Rehemtulla A, Ross BD. Functional diffusion map: a noninvasive MRI biomarker for early stratification of clinical brain tumor response. Proc Natl Acad Sci U S A. 2005; 102: 5524-9.

64. Galban CJ, Chenevert TL, Meyer CR, Tsien C, Lawrence TS, Hamstra DA, Junck L, Sundgren PC, Johnson TD, Ross DJ, Rehemtulla A, Ross BD. The parametric response map is an imaging biomarker for early cancer treatment outcome. Nat Med. 2009; 15: 572-6.

65. Cho N, Im SA, Park IA, Lee KH, Li M, Han W, Noh DY, Moon WK. Breast cancer: early prediction of response to neoadjuvant chemotherapy using parametric response maps for MR imaging. Radiology. 2014; 272: 385-96.

66. Lee KC, Hall DE, Hoff BA, Moffat BA, Sharma S, Chenevert TL, Meyer CR, Leopold WR, Johnson TD, Mazurchuk RV, Rehemtulla A, Ross BD. Dynamic imaging of emerging resistance during cancer therapy. Cancer Res. 2006; 66: 4687-92.

67. Clemenson C, Chargari C, Deutsch E. Combination of vascular disrupting agents and ionizing radiation. Critical reviews in oncology/hematology. 2013; 86: 143-60.

68. Siemann DW, Shi W. Dual targeting of tumor vasculature: combining Avastin and vascular disrupting agents (CA4P or OXi4503). Anticancer research. 2008; 28: 2027-31.

69. Siemann DW, Shi W. Efficacy of combined antiangiogenic and vascular disrupting agents in treatment of solid tumors. Int J Radiat Oncol Biol Phys. 2004; 60: 1233-40.

70. Chung F, Liu J, Ching LM, Baguley BC. Consequences of increased vascular permeability induced by treatment of mice with 5,6-dimethylxanthenone-4-acetic acid (DMXAA) and thalidomide. Cancer chemotherapy and pharmacology. 2008; 61: 497-502.

71. Nathan P, Zweifel M, Padhani AR, Koh DM, Ng M, Collins DJ, Harris A, Carden C, Smythe J, Fisher N, Taylor NJ, Stirling JJ, Lu SP, Leach MO, Rustin GJ, Judson I. Phase I trial of combretastatin A4 phosphate (CA4P) in combination with bevacizumab in patients with advanced cancer. Clin Cancer Res. 2012; 18: 3428-39.

72. Blakey DC, Westwood FR, Walker M, Hughes GD, Davis PD, Ashton SE, Ryan AJ. Antitumor activity of the novel vascular targeting agent ZD6126 in a panel of tumor models. Clin Cancer Res. 2002; 8: 1974-83. 
73. Cesca M, Bizzaro F, Zucchetti M, Giavazzi R. Tumor delivery of chemotherapy combined with inhibitors of angiogenesis and vascular targeting agents. Frontiers in oncology. 2013; 3: 259.

74. Mitrus I, Sochanik A, Cichon T, Szala S. Combination of combretastatin A4 phosphate and doxorubicin-containing liposomes affects growth of B16-F10 tumors. Acta biochimica Polonica. 2009; 56: 161-5.

75. Daenen LG, Shaked Y, Man S, Xu P, Voest EE, Hoffman RM, Chaplin DJ, Kerbel RS. Low-dose metronomic cyclophosphamide combined with vascular disrupting therapy induces potent antitumor activity in preclinical human tumor xenograft models. Molecular cancer therapeutics. 2009; 8: 2872-81.

76. Ng QS, Mandeville H, Goh V, Alonzi R, Milner J, Carnell D, Meer K, Padhani AR, Saunders MI, Hoskin PJ. Phase Ib trial of radiotherapy in combination with combretastatinA4-phosphate in patients with non-small-cell lung cancer, prostate adenocarcinoma, and squamous cell carcinoma of the head and neck. Annals of oncology. 2012; 23: 231-7.

77. Meyer T, Gaya AM, Dancey G, Stratford MR, Othman S, Sharma SK, Wellsted D, Taylor NJ, Stirling JJ, Poupard L, Folkes LK, Chan PS, Pedley RB, Chester KA, Owen $\mathrm{K}$, Violet JA, Malaroda A, Green AJ, Buscombe J, Padhani AR, Rustin GJ, Begent RH. A phase I trial of radioimmunotherapy with 131I-A5B7 anti-CEA antibody in combination with combretastatin-A4-phosphate in advanced gastrointestinal carcinomas. Clin Cancer Res. 2009; 15: 4484-92.

78. Pedley RB, Hill SA, Boxer GM, Flynn AA, Boden R, Watson R, Dearling J, Chaplin DJ, Begent RH. Eradication of colorectal xenografts by combined radioimmunotherapy and combretastatin a-4 3-O-phosphate. Cancer Res. 2001; 61: 4716-22.

79. Wilczynski J, Duechler M, Czyz M. Targeting NF-kappaB and HIF-1 pathways for the treatment of cancer: part I. Archivum immunologiae et therapiae experimentalis. 2011; 59: 289-99.

80. Li J, Cona MM, Chen F, Feng Y, Zhou L, Yu J, Nuyts J, de Witte P, Zhang J, Himmelreich U, Verbruggen A, Ni Y. Exploring theranostic potentials of radioiodinated hypericin in rodent necrosis models. Theranostics. 2012; 2: 1010-9.

81. Li J, Cona MM, Chen F, Feng Y, Zhou L, Zhang G, Nuyts J, de Witte P, Zhang J, Yu J, Oyen R, Verbruggen A, Ni Y. Sequential systemic administrations of combretastatin A4 Phosphate and radioiodinated hypericin exert synergistic targeted theranostic effects with prolonged survival on SCID mice carrying bifocal tumor xenografts. Theranostics. 2013; 3: 127-37.

82. Li J, Sun Z, Zhang J, Shao H, Cona MM, Wang H, Marysael T, Chen F, Prinsen K, Zhou L, Huang D, Nuyts J, Yu J, Meng B, Bormans G, Fang Z, de Witte P, Li Y, Verbruggen A, Wang X, Mortelmans L, Xu K, Marchal G, Ni Y. A dual-targeting anticancer approach: soil and seed principle. Radiology. 2011; 260: 799-807.
83. Song S, Xiong C, Zhou M, Lu W, Huang Q, Ku G, Zhao J, Flores LG, Jr., Ni Y, Li C. Small-animal PET of tumor damage induced by photothermal ablation with $64 \mathrm{Cu}$-bisDOTA-hypericin. J Nucl Med. 2011; 52: 792-9.

84. Shao H, Zhang J, Sun Z, Chen F, Dai X, Li Y, Ni Y, $\mathrm{Xu}$ K. Necrosis targeted radiotherapy with iodine131-labeled hypericin to improve anticancer efficacy of vascular disrupting treatment in rabbit VX2 tumor models. Oncotarget. 2015; 6: 14247-59. doi: 10.18632/ oncotarget.3679.

85. Shaked Y, Bertolini F, Man S, Rogers MS, Cervi D, Foutz T, Rawn K, Voskas D, Dumont DJ, Ben-David Y, Lawler J, Henkin J, Huber J, Hicklin DJ, D'Amato RJ, Kerbel RS. Genetic heterogeneity of the vasculogenic phenotype parallels angiogenesis; Implications for cellular surrogate marker analysis of antiangiogenesis. Cancer Cell. 2005; 7: 101-11.

86. Thomas DA, Kantarjian HM. Current role of thalidomide in cancer treatment. Current opinion in oncology. 2000; 12 : 564-73.

87. Jain RK. Normalization of tumor vasculature: an emerging concept in antiangiogenic therapy. Science. 2005; 307: 5862.

88. Kim TJ, Ravoori M, Landen CN, Kamat AA, Han LY, Lu C, Lin YG, Merritt WM, Jennings N, Spannuth WA, Langley R, Gershenson DM, Coleman RL, Kundra V, Sood AK. Antitumor and antivascular effects of AVE8062 in ovarian carcinoma. Cancer Res. 2007; 67: 9337-45.

89. Shaked Y, Emmenegger U, Man S, Cervi D, Bertolini F, Ben-David Y, Kerbel RS. Optimal biologic dose of metronomic chemotherapy regimens is associated with maximum antiangiogenic activity. Blood. 2005; 106: 305861.

90. Bertolini F, Paul S, Mancuso P, Monestiroli S, Gobbi A, Shaked Y, Kerbel RS. Maximum tolerable dose and lowdose metronomic chemotherapy have opposite effects on the mobilization and viability of circulating endothelial progenitor cells. Cancer Res. 2003; 63: 4342-6.

91. Giavazzi R, Bani MR, Taraboletti G. Tumor-host interaction in the optimization of paclitaxel-based combination therapies with vascular targeting compounds. Cancer metastasis reviews. 2007; 26: 481-8.

92. Siemann DW, Mercer E, Lepler S, Rojiani AM. Vascular targeting agents enhance chemotherapeutic agent activities in solid tumor therapy. Int J Cancer. 2002; 99: 1-6.

93. Murata R, Siemann DW, Overgaard J, Horsman MR. Interaction between combretastatin A-4 disodium phosphate and radiation in murine tumors. Radiotherapy and oncology. 2001; 60: 155-61.

94. Wilson WR, Li AE, Cowan DS, Siim BG. Enhancement of tumor radiation response by the antivascular agent 5,6-dimethylxanthenone-4-acetic acid. Int J Radiat Oncol Biol Phys. 1998; 42: 905-8.

95. Murata R, Siemann DW, Overgaard J, Horsman MR. 
Improved tumor response by combining radiation and the vascular-damaging drug 5,6-dimethylxanthenone-4-acetic acid. Radiation research. 2001; 156: 503-9.

96. Martinelli M, Bonezzi K, Riccardi E, Kuhn E, Frapolli R, Zucchetti M, Ryan AJ, Taraboletti G, Giavazzi R. Sequence dependent antitumour efficacy of the vascular disrupting agent ZD6126 in combination with paclitaxel. Br J Cancer. 2007; 97: 888-94.

97. Chaplin DJ, Horsman MR, Siemann DW. Current development status of small-molecule vascular disrupting agents. Current opinion in investigational drugs (London, England : 2000). 2006; 7 : 522-8.

98. Bouzin C, Feron O. Targeting tumor stroma and exploiting mature tumor vasculature to improve anti-cancer drug delivery. Drug resistance updates. 2007; 10: 109-20.

99. Patterson DM, Rustin GJ. Vascular damaging agents. Clinical oncology (Royal College of Radiologists (Great Britain)). 2007; 19: 443-56.

100. Pollard JW. Tumour-educated macrophages promote tumour progression and metastasis. Nat Rev Cancer. 2004; 4: 71-8.

101. Raben D, Bianco C, Damiano V, Bianco R, Melisi D, Mignogna C, D'Armiento FP, Cionini L, Bianco AR, Tortora G, Ciardiello F, Bunn P. Antitumor activity of ZD6126, a novel vascular-targeting agent, is enhanced when combined with ZD1839, an epidermal growth factor receptor tyrosine kinase inhibitor, and potentiates the effects of radiation in a human non-small cell lung cancer xenograft model. Molecular cancer therapeutics. 2004; 3: 977-83.

102. Koh DM, Blackledge M, Collins DJ, Padhani AR, Wallace T, Wilton B, Taylor NJ, Stirling JJ, Sinha R, Walicke P, Leach MO, Judson I, Nathan P. Reproducibility and changes in the apparent diffusion coefficients of solid tumours treated with combretastatin A4 phosphate and bevacizumab in a two-centre phase I clinical trial. Eur Radiol. 2009; 19: 2728-38.

103. Jorgensen TJ, Tian H, Joseph IB, Menon K, Frost D. Chemosensitization and radiosensitization of human lung and colon cancers by antimitotic agent, ABT-751, in athymic murine xenograft models of subcutaneous tumor growth. Cancer chemotherapy and pharmacology. 2007; 59: 725-32.

104. Li L, Rojiani A, Siemann DW. Targeting the tumor vasculature with combretastatin A-4 disodium phosphate: effects on radiation therapy. Int J Radiat Oncol Biol Phys. 1998; 42: 899-903.

105. Iversen AB, Busk M, Horsman MR. Induction of hypoxia by vascular disrupting agents and the significance for their combination with radiation therapy. Acta oncologica (Stockholm, Sweden). 2013; 52: 1320-6.

106. Siemann DW, Rojiani AM. Enhancement of radiation therapy by the novel vascular targeting agent ZD6126. Int J Radiat Oncol Biol Phys. 2002; 53: 164-71.
107. Masunaga S, Nagasawa H, Nagata K, Suzuki M, Uto Y, Hori H, Kinashi Y, Ono K. Dependency of the effect of a vascular disrupting agent on sensitivity to tirapazamine and gamma-ray irradiation upon the timing of its administration and tumor size, with reference to the effect on intratumor quiescent cells. Journal of cancer research and clinical oncology. 2007; 133: 47-55.

108. Siemann DW, Rojiani AM. The vascular disrupting agent ZD6126 shows increased antitumor efficacy and enhanced radiation response in large, advanced tumors. Int J Radiat Oncol Biol Phys. 2005; 62: 846-53.

109. Lankester KJ, Maxwell RJ, Pedley RB, Dearling JL, Qureshi UA, El-Emir E, Hill SA, Tozer GM. Combretastatin A-4phosphate effectively increases tumor retention of the therapeutic antibody, 131I-A5B7, even at doses that are sub-optimal for vascular shut-down. International journal of oncology. 2007; 30: 453-60.

110. Kacerovska D, Pizinger K, Majer F, Smid F. Photodynamic therapy of nonmelanoma skin cancer with topical hypericum perforatum extract - a pilot study. Photochem Photobiol. 2008; 84: 779-85.

111. Olivo M, Du HY, Bay BH. Hypericin lights up the way for the potential treatment of nasopharyngeal cancer by photodynamic therapy. Curr Clin Pharmacol. 2006; 1: 217 22.

112. Olivo M, Lau W, Manivasager V, Bhuvaneswari R, Wei Z, Soo KC, Cheng C, Tan PH. Novel photodynamic diagnosis of bladder cancer: ex vivo fluorescence cytology using hypericin. Int J Oncol. 2003; 23: 1501-4.

113. Rook AH, Wood GS, Duvic M, Vonderheid EC, Tobia A, Cabana B. A phase II placebo-controlled study of photodynamic therapy with topical hypericin and visible light irradiation in the treatment of cutaneous T-cell lymphoma and psoriasis. J Am Acad Dermatol. 2010; 63: 984-90.

114. Van de Putte M, Wang H, Chen F, De Witte PA, Ni Y. Hypericin as a marker for determination of tissue viability after radiofrequency ablation in a murine liver tumor model. Oncol Rep. 2008; 19: 927-32.

115. Van de Putte M, Roskams T, Vandenheede JR, Agostinis $\mathrm{P}$, de Witte PA. Elucidation of the tumoritropic principle of hypericin. Br J Cancer. 2005; 92: 1406-13.

116. Van de Putte M, Ni Y, De Witte PA. Exploration of the mechanism underlying the tumor necrosis avidity of hypericin. Oncol Rep. 2008; 19: 921-6.

117. Van de Putte M, Marysael T, Fonge H, Roskams T, Cona MM, Li J, Bormans G, Verbruggen A, Ni Y, de Witte PA. Radiolabeled iodohypericin as tumor necrosis avid tracer: diagnostic and therapeutic potential. Int J Cancer. 2012; 131: E129-37.

118. Ni Y, Huyghe D, Verbeke K, de Witte PA, Nuyts J, Mortelmans L, Chen F, Marchal G, Verbruggen AM, Bormans GM. First preclinical evaluation of mono-[123I] iodohypericin as a necrosis-avid tracer agent. Eur J Nucl 
Med Mol Imaging. 2006; 33: 595-601.

119. Belhocine TZ, Prato FS. Transbilayer phospholipids molecular imaging. EJNMMI Res. 2011; 1: 17. 